\title{
A STUDY OF INCIDENCE AND PROGNOSTIC SIGNIFICANCE OF RENAL IMPAIRMENT IN PATIENTS SUFFERING FROM MALARIA
}

\author{
Maya ${ }^{1}$, Kumar Bipin'2, Kumar Ajay³ ${ }^{3}$ Achari Vijay4, Singh Rashmi ${ }^{5}$, Singh Kumar Sudhir 6
}

${ }^{1}$ Senior Resident, Department of Cardiology, RIMS, Ranchi.

${ }^{2}$ Tutor, Department of Community Medicine, PMCH, Patna.

${ }^{3}$ Senior Resident, Department of Microbiology, IGIMS, Patna.

${ }^{4}$ Professor, Department of Medicine, PMCH, Patna.

5 Professor, Department of Community Medicine, PMCH, Patna.

${ }^{6}$ Associate Professor, Department of Medicine, PMCH, Patna.

\begin{tabular}{l}
\hline ABSTRACT \\
BACKGROUND \\
Malaria is probably one of the oldest diseases known to mankind that has had profound impact on our history. It continues to be a \\
huge social, economic and health problem, particularly in the tropical countries. \\
The aims of this study are to study- \\
1. Incidence and severity of renal impairment in patients confirmed to be suffering from malaria. \\
2. Short-term prognostic significance of renal impairment (in-hospital mortality and morbidity). \\
3. Correlation with other parameters of severe malaria as per WHO criteria.
\end{tabular}

\section{MATERIALS AND METHODS}

A descriptive study was carried out on 100 patients of malaria, admitted in Department of Medicine, Patna Medical College and Hospital, Patna, a tertiary level hospital. The study period extended from January 2010 to August 2011.

\section{RESULTS}

Out of 100 cases diagnosed as malaria and admitted in medical ward, emergency and ICU were included for this study. 30 cases were diagnosed as having acute kidney injury as per RIFLE/AKIN criteria in cases of malaria and comprised of different age groups ranging from 15 - 75 years and both sexes with male: female ratio of 3.0: 1.

\section{CONCLUSION}

It is therefore suggested that early diagnosis of falciparum malaria and prompt treatment may help in preventing many of the devastating complications of their disease including renal or multi-organ dysfunction.

\section{KEYWORDS}

Renal Impairment, Malaria.

HOW TO CITE THIS ARTICLE: Maya, Bipin K, Ajay K, et al. A study of incidence and prognostic significance of renal impairment in patients suffering from malaria. J. Evolution Med. Dent. Sci. 2017;6(87):6011-6015, DOI: 10.14260/jemds/2017/1307

\section{BACKGROUND}

Malaria is a protozoal disease transmitted by the bite of infected anopheles mosquitoes. It is the most important of the parasitic diseases of humans with transmission in 107 countries containing 3 billion people and causing 1 - 3 million deaths each year. Malaria is a major cause of mortality and morbidity in the tropical and subtropical regions of the world. Developed countries are relatively free of malaria, but it remains well entrenched across the tropical world. ${ }^{1}$

The incidence of malaria worldwide is estimated to be 300 - 500 million clinical cases each year with about 90 percent of these occurring in Sub-Saharan Africa, and mostly caused by P. falciparum. India accounts for 77 percent of the regional total. Major endemic areas of India account for 77

'Financial or Other Competing Interest': None.

Submission 30-08-2017, Peer Review 18-10-2017,

Acceptance 25-10-2017, Published 30-10-2017.

Corresponding Author:

Dr. Ajay Kumar,

Senior Resident,

Department of Microbiology,

Indira Gandhi Institute of Medical Sciences (IGIMS),

Patna-14.

E-mail: dr.ajay876@gmail.com

DOI: $10.14260 /$ jemds $/ 2017 / 1307$

\section{(c) $(1)$} percent of the regional total. Major endemic areas in India are in the North-Eastern states, Andhra Pradesh, Chhattisgarh, Gujarat, Jharkhand, Bihar, Madhya Pradesh, Maharashtra, Rajasthan and Orissa. ${ }^{2}$

Five species of the genus Plasmodium cause nearly all malarial infections in humans. These are P. falciparum, P. vivax, P. ovale, P. malariae and in Southeast Asia- the monkey malaria parasite P. knowlesi, which can be reliably identified only by molecular methods. Almost all deaths are caused by falciparum malaria. Human infection begins when a female anopheles mosquito inoculates plasmodium sporozoites from its salivary gland during a blood meal. These microscopic motile forms of the malaria parasite are carried rapidly via the bloodstream to the liver, where they invade hepatic parenchymal cells and begin a period of asexual reproduction. By this amplification process (known as intrahepatic or pre-erythrocytic schizogony or merogony), a single sporozoite eventually may produce from 10,000 to $>30,000$ daughter merozoites. The swollen infected liver cell eventually bursts, discharging motile merozoites into the bloodstream. These merozoites then invade the red blood cells (RBCs) and multiply six to twenty-fold every $48-72 \mathrm{~h}$. When the parasites reach densities of 50/ $\mathrm{L}$ of blood $(100$ million parasites in the blood of an adult), the symptomatic stage of the infection begins. In $P$. vivax and $P$. ovale 
infections, a proportion of the intrahepatic forms do not divide immediately, but remain dormant for a period ranging from 3 weeks to a year or longer before reproduction begins. These dormant forms or hypnozoites are the cause of the relapses that characterise infection with these two species. ${ }^{3}$

Symptoms of malaria include fever, shivering, arthralgia, vomiting, anaemia, haemolysis and jaundice, haemoglobinuria and convulsions. There may be a feeling of tingling in the skin, particularly with malaria caused by $\mathrm{P}$. falciparum.

The classical symptom of malaria is cyclical occurrence of sudden coldness followed by rigor and then fever and sweating lasting four to six hours, occurring every two days in P. vivax and P. ovale infections, while every three for P. malariae and P. falciparum can have recurrent fever every 36-48 hours or a less pronounced and almost continuous fever. Splenomegaly, severe headache, cerebral ischaemia, hepatomegaly, hypoglycaemia and haemoglobinuria with renal failure may occur. Chronic malaria is seen in both $P$. vivax and P. ovale, but not in P. falciparum. Here, the disease can relapse months or years after exposure due to the presence of latent parasites in the liver. Describing a case of malaria as cured by observing the disappearance of parasites from the bloodstream can therefore be deceptive. Severe malaria should be suspected in patients with confirmed malaria and who have severe manifestations. If the patients with falciparum malaria have jaundice, vital organ complications should be looked for. Also hyperpyrexia is no longer considered a sign of severity. The diagnosis of malaria is essentially made from clinical features and can be confirmed by demonstration of plasmodium by laboratory examination.

\section{MATERIALS AND METHODS}

A descriptive study was carried out on 100 patients of malaria admitted in Department of Medicine, Patna Medical College and Hospital, Patna, a tertiary level hospital. The study period extended from January 2010 to August 2011. Cases were selected with complaint of untreated fever of short duration and/or raised body temperature without any pre-existing documented systemic illness. Definite diagnosis of malaria was finally with clinical features like fever-paroxysmal, remittent or intermittent, chills, anaemia, splenomegaly, hepatomegaly, headache, vomiting, drowsiness, altered behaviour, confusion, unarousable coma, etc. The following investigations were done in all cases of primary pool to establish the diagnosis of malaria and to rule out other systemic illnesses-

1. Confirmation of diagnosis was made by demonstration of plasmodium in the peripheral blood by thin and thick blood film examination.

2. By immunochromatographic test.

3. Quantitative Buffy coat analysis for parasite.

4. Complete blood profile included platelet.

5. Routine examination of urine.

6. Random or fasting blood sugar.

7. Serum bilirubin and liver enzyme estimation [ALT, AST], serum protein.

8. Coagulation profile- APTT, PT [INR].

9. Blood urea and serum creatinine.

10. Serum electrolytes [sodium and potassium].
The above investigations were done at the time of admission in all cases, thereafter cases with renal impairment were advised to report again after 6 weeks. They were investigated for blood urea and serum creatinine and serum electrolyte. The results were compared to those found in the first week of admission.

\section{Statistical Analysis}

The data collection was entered in the Microsoft Excel computer program using SPSS version 16.0. Percentages were calculated for categorical variables and checked for any indiscrepancy. Fisher's exact test was used and the result was presented in proportion/ percentages.

\section{Ethical Consideration}

Ethical clearance was taken from Institutional Ethical Committee of Patna Medical College and Hospital, Patna. The consent was taken from each patient included in the study.

\section{RESULT}

Out of 100 cases, 30 cases of renal impairment were chosen on the basis of RIFLE/AKIN criteria for acute kidney injury. All the cases with renal impairment were followed up after 6 weeks with different renal parameters. The outcome of the study was tabulated statistically. Out of 100 cases studied, 77 were male and 23 were female. The age of patient varied from 13 - 75 years. The maximum incidence of the disease was observed among patients in the age group from 21 years to 40 years in both sexes.

Out of 100 cases 62 were diagnosed by light microscopy in peripheral blood smears, 95 cases were diagnosed by immunochromatography [Optimal IT]. Out of these 100 patients 68 cases had Plasmodium falciparum infection, 27 had malaria from P. vivax and 5 patients had combined falciparum and vivax infection.

Out of 30 cases of renal failure, 25 cases $(83.3 \%)$ were P. falciparum with mortality rate of $81.8 \%, 2(6.6 \%)$ cases were P. vivax with no mortality and 3 cases $(10 \%)$ were both falciparum and vivax positive with mortality rate of $18.18 \%$ [Table 1].

\begin{tabular}{|c|c|c|c|c|}
\hline $\begin{array}{c}\text { Plasmodium } \\
\text { Species }\end{array}$ & No. & Percentage & \multicolumn{2}{|c|}{ Mortality } \\
\hline & & & No. & Percentage \\
\hline P. falciparum & 25 & 83.3 & 9 & 36 \\
\hline P. vivax & 2 & 6.66 & - & - \\
\hline Combined & 3 & 10 & 2 & 67 \\
\hline \multicolumn{2}{|c|}{ Table 1. Showing Mortality in Cases of Renal Failure } \\
\hline
\end{tabular}

due to Different Types of Malarial Parasite $(n=30)$

Out of 100 cases, 30 cases showed serum creatinine $>1.5$ times baseline or creatinine rise $>0.3$ over 48 hours and/or urine output less than $0.5 \mathrm{~mL} / \mathrm{kg} / \mathrm{hr}$ for 6 hours.

\begin{tabular}{|c|c|c|}
\hline Parameters & No. & Percentage (\%) \\
\hline $\begin{array}{c}\text { Serum creatinine }>1.5 \text { times baseline } \\
\text { or creatinine rise }>0.3 \text { over 48 hours }\end{array}$ & 30 & 30 \\
\hline $\begin{array}{c}\text { Decreased urine output less than } \\
0.5 \mathrm{~mL} / \mathrm{kg} / \mathrm{hr} \text { for } 6 \text { hours }\end{array}$ & 24 & 24 \\
\hline Table 2. Evidence of Impaired Renal Function \\
in Cases of Malaria (n= 100) \\
\hline Out of 30 cases of ARF 27 cases (90\%) showed
\end{tabular}
proteinuria, 19 cases (63.33\%) showed casts, red blood cells 
in $16(53.33 \%)$ and bile salt and bile pigment was seen in 15 cases $(50 \%)$.

\begin{tabular}{|c|c|c|c|}
\hline Sl. No. & Findings & No. & Percentage \\
\hline 1 & Proteinuria & 27 & 90 \\
\hline 2 & Cast (hyaline and granular) & 19 & 63.33 \\
\hline 3 & Red blood cells & 16 & 53.33 \\
\hline 4 & Bile salt and bile pigment & 15 & 50 \\
\hline
\end{tabular}

Table 3. Routine Examination of Urine (with Microscopic Examination) in Cases of Renal Impairment in Malaria

Out of 30 cases of renal failure, 24 cases $(80 \%)$ were oliguric with mortality rate of $41.66 \%$ and 6 cases $(20 \%)$ were non-oliguric with mortality rate of $16.67 \%$ [Table 4].

\begin{tabular}{|c|c|c|c|c|}
\hline Type of Renal Failure & No. & Percentage & \multicolumn{2}{|c|}{ Mortality } \\
\hline \multicolumn{3}{|c|}{} & No. & Percentage \\
\hline Oliguric & 24 & 80 & 10 & 41.66 \\
\hline Non-oliguric & 6 & 20 & 1 & 16.67 \\
\hline $\begin{array}{r}\text { Table 4. Percentage of Oliguric and Non-Oliguric Renal } \\
\text { Failure in Plasmodium induced ARF (n= 30) }\end{array}$ \\
\hline
\end{tabular}

Out of 30 cases of oliguric renal failure, 17 cases were managed with haemodialysis. Dialysis was done in only 2 cases of non-oliguric renal failure [Table 5].

\begin{tabular}{|c|c|c|c|}
\hline Type of Renal Failure & No. (n= 30) & Dialysis & Percentage \% \\
\hline Oliguric & 24 & 17 & 70.8 \\
\hline Non-oliguric & 6 & 2 & 33.33 \\
\hline Table 5. Dialysis in Cases of Renal Failure (n= 30) \\
\hline
\end{tabular}

Antimalarials were given in all the 30 cases of renal impairment, out of which 11 (36.6\%) having mild renal impairment were managed conservatively with rehydration and/or diuretics with mortality of $18.8 \%$ and fewer complications, while 19 (63.3\%) were having moderate-tosevere renal impairment were managed with haemodialysis with mortality $(47.36 \%)$ due to severe complication of malaria with multisystem involvement. The above table shows that dialysis was associated with a higher mortality in patients with ARF, but it was not significant statistically ( $p$ value $>0.05$ ) [Table 6].

\begin{tabular}{|c|c|c|c|c|c|}
\hline Sl. No. & Management & No. & \% & Mortality & $\%$ \\
\hline 1. & $\begin{array}{c}\text { Antimalarial without } \\
\text { Dialysis }\end{array}$ & 11 & 36.6 & 2 & 18.18 \\
\hline 2. & $\begin{array}{c}\text { Antimalarial with } \\
\text { Dialysis }\end{array}$ & 19 & 63.3 & 9 & 47.36 \\
\hline \multicolumn{5}{|c|}{$\begin{array}{c}\text { Table 6. Management and Outcome in } \\
\text { Cases of Renal Failure in Malaria (n= 30) }\end{array}$} \\
\hline
\end{tabular}

P-value $=0.1395$ (Fisher's exact test)

Out of 11 cases that expired $4(36.3 \%)$ were severely anaemic, $3(27.2 \%)$ developed pulmonary oedema/ ARDS; 7 cases $(63.3 \%)$ had hyperbilirubinaemia, 5 cases $(45.4 \%)$ had severe infection, 7 cases (63.3\%) had cerebral malaria and 9 cases (81.8\%) had hypoglycaemia. More than one complication was seen in a patient at a time [Table 7].

\begin{tabular}{|c|c|c|c|}
\hline $\begin{array}{c}\text { Sl. } \\
\text { No. }\end{array}$ & Complication & $\begin{array}{c}\text { No. of } \\
\text { Patients Died }\end{array}$ & $\begin{array}{c}\text { Percentage } \\
\text { (\%) }\end{array}$ \\
\hline 1. & Severe Anaemia & 4 & 36.3 \\
\hline 2. & Pulmonary Oedema/ ARDS & 3 & 27.2 \\
\hline 3. & Hyperbilirubinaemia & 7 & 63.3 \\
\hline 4. & Hypoglycaemia & 9 & 81.8 \\
\hline 5. & Cerebral Malaria & 7 & $63.3 \%$ \\
\hline 6. & Infection & 5 & 45.4 \\
\hline \multicolumn{3}{|c|}{ Table 7. Various Risk Factors associated with } \\
Mortality in Cases of Acute Renal Failure (n= 11) \\
\hline
\end{tabular}

In 19 cases, out of 30 that survived the mean serum creatinine was $3.91 \mathrm{mg} / \mathrm{dL}$, SD 1.97; mean haemoglobin 9.63, SD 3.05; mean serum potassium 4.26, SD 1.04; mean serum sodium 132.26, SD 9.13; mean ALT 91.89, SD 84.03; mean blood sugar 72.47, SD 33.66; mean serum bilirubin 3.832, SD 3.037 .

In 11 cases, out of 30 patients of ARF that expired, the mean serum creatinine was $8.03 \mathrm{mg} / \mathrm{dL}$, SD 4.42; mean haemoglobin 7.91, SD 3.5; mean serum potassium 4.98, SD 1.21; mean serum sodium 124.64, SD 10.56; mean ALT 107, SD 66.26; mean blood sugar 45, SD 24.03; mean serum bilirubin 5.1, SD 4.86 [Table 8].

\begin{tabular}{|l|c|c|c|c|}
\hline & \multicolumn{2}{|c|}{ Survived Cases } & \multicolumn{2}{c|}{ Expired Cases } \\
\hline \multicolumn{1}{|c|}{ Parameters } & Mean & SD & Mean & SD \\
\hline 1. Serum Creatinine & 3.91 & 1.97 & 8.03 & 4.42 \\
\hline 2. Haemoglobin & 9.63 & 3.05 & 7.91 & 3.5 \\
\hline 3. Serum Sodium & 132.26 & 9.13 & 124.64 & 10.56 \\
\hline 4. Serum Potassium & 4.26 & 1.04 & 4.98 & 1.21 \\
\hline 5. ALT & 91.89 & 84.03 & 107 & 66.26 \\
\hline 6. Blood Sugar & 72.47 & 33.66 & 45 & 24.03 \\
\hline 7. Serum Bilirubin & 3.832 & 3.037 & 5.1 & 4.86 \\
\hline
\end{tabular}

Table 8. Different Parameters in Case of ARF in Malaria with Mean and Standard Deviation

\section{DISCUSSION}

Acute kidney injury (AKI) is a serious complication of malaria, mostly in falciparum malaria that carries a high mortality. Out of 100 cases 62 were diagnosed by light microscopy in peripheral blood smears, 95 were diagnosed by immunochromatography (optimal) and 65 were diagnosed by Buffy coat examination. These 68 cases had P. falciparum infection alone, 27 had P. vivax infection and 5 cases have combined P. falciparum and P. vivax infection. Mahakur et al $(1983,1992)$ also included combined cases in their study; $77 \%$ of total cases were male and $23 \%$ were female. ${ }^{4}$ This male predominance is difficult to explain, but is supported from other studies. The age of patients varied from 15 - 75 years. The maximum incidence of the disease was observed among patients in the age group from 21 - 40 years in both sexes. Prakash et al (1996) also reported maximum incidence of the disease in age range from 15 - 85 years. ${ }^{5}$ Incidence was found higher in males, probably because they are more exposed to outdoors. This is in agreement with findings of Kulkarni et al (2000), T. Shabab et al (2003) and Anil K Mohanty et al (2004). ${ }^{6}$ In study of Krishna et al (2003) there were hepatic failure in 77, ARDS in 77, hypoglycaemia in 88 and sepsis in 39 cases out of 301 cases. In our study, 24 cases presented with diminished urine output and 18 with dark coloured urine. Nityanand et al (1997) reported oliguria 
in $50 \%$ cases. In the present study, 48 cases presented with hepatomegaly and 86 cases with splenomegaly. ${ }^{7}$ Mohanty et al (2004) found hepatomegaly in $72 \%$ cases and splenomegaly in $80 \%$ cases respectively. Newton et al (2003) found similar results. All the above findings showed that malaria along with renal involvement also had multisystem involvement in various ways and effects on prognosis of the disease. In our study, 44 cases showed serum bilirubin $>3$ $\mathrm{mg} / \mathrm{dL}$ and 37 showed ALT > $100 \mathrm{U} / \mathrm{L}$. Marsh et al (1995) found similar observation. ${ }^{8}$ In our study among extrarenal involvement and its outcome in total patients ( $\mathrm{n}=100), 22 \%$ were severely anaemic with $\mathrm{Hb} \%<5 \mathrm{gm} / \mathrm{dL}$, out of which 4 cases died; 44 showed hepatic involvement with serum bilirubin $>3 \mathrm{mg} / \mathrm{dL}$, out of which 7 died; 28 patients had cerebral malaria, out of which 7 (25\%) died; 3\% had developed pulmonary oedema/ ARDS with 100\% mortality; $29 \%$ were hypoglycaemic (blood sugar $<40 \mathrm{gm} / \mathrm{dL}$ ) at the time of admission, out of which 31\% died. Hyponatraemia < $135 \mathrm{mEq} / \mathrm{L}$ ) was present in $41 \%$ cases with $21.9 \%$ mortality and hyperkalaemia (> $5 \mathrm{mEq} / \mathrm{L}$ ) in $22 \%$, out of which 5 $(22.72 \%)$ died. Similar extrarenal involvement was observed by different workers. Prakash J et al (1996), Segasothy M (1994) and Trang TT et al (1992) has similar observation. ${ }^{9}$ In our study renal impairment was detected on the basis of serum creatinine $>1.5$ times baseline or rise in serum creatinine $>0.3 \mathrm{mg} / \mathrm{dL}$ and/or oliguria $(<0.5 \mathrm{~mL} / \mathrm{kg}$ for 6 hours). Out of 100 cases, 30 (30\%) showed acute kidney injury on the basis of mentioned criteria. This finding corresponded well with the findings of other workers. Rath et al (1990) reported 38.4\%, A. Sowunmi et al (1996) reported $45 \%$, Sitprija et al (1970) reported $66.6 \%$ and Patis et al (2003) reported $51 \%$ incidence of renal failure due to falciparum malaria in their study. Renal involvement in malaria varies widely from mild-to-moderate proteinuria with accompanying urinary sediments containing RBCs and granular and/ or hyaline cast and bile salts and bile pigments if associated with hepatic involvement. In our study, out of 30 cases of ARF 27 cases (90\%) showed proteinuria, 19 (63.3\%) showed casts, red blood cells in $16(53.3 \%)$ and bile salt and bile pigment in 15 cases (50\%). Proteinuria was also supported by study of different workers. Mild proteinuria was reported in $28.6 \%$ by Sitprija et al 1970 , in $38.4 \%$ by Rath et al 1990, in $40 \%$ by Sowunmi et al 1996 and in $57.7 \%$ by Prakash et al 1996 respectively in their study. Bile salts and bile pigments in urine observed in patients of ARF is highly suggestive of hyperbilirubinaemia and intrahepatic cholestasis as reported by Dash SC et al (1994) and Segasothy $M$ et al (1994). Among patients with ARF mean creatinine was $5.42 \mathrm{mg} / \mathrm{dL}$, mean serum sodium was $129.3 \mathrm{mEq} / \mathrm{L}$ and mean serum potassium was $4.52 \mathrm{mEq} / \mathrm{L}$. In the study by Segasothy M et al (1994), the mean serum $\mathrm{Na}+$ was slightly lower than normal range and serum $\mathrm{K}+$ were within normal range, though hyperkalaemia was observed in $36 \%$ of cases, which bore poor prognosis. ${ }^{10}$ In the study of A. Sowunmi et al 1996, hyponatraemia occurred in $12.5 \%$ during the acute phase. Patients with renal failure have impairment of elimination of nitrogenous wastes, water, electrolyte and acid. Sitprija et al (1970) described mild proteinuria of less than $500 \mathrm{mg}$ /day in $28 \%$ of cases. Rath et al (1990) in their studies observed proteinuria of $<1 \mathrm{gm} /$ day in $34.8 \%$ cases. Berger et al (1967) in their report of 3 cases found proteinuria in excess of $3.5 \mathrm{gm} / 24 \mathrm{hrs} .^{11}$ In our study out of
30 patients of renal failure, parasite count was found to be more than $100,000 / \mu \mathrm{L}$ in 23 patients, out of which 13 patients survived. In our study, out of 30 cases of renal failure, 24 cases $(80 \%)$ were oliguric with mortality of $41.6 \%$. ARF in malaria is usually oliguric and hypercatabolic and oliguric phase lasts for a few days to several weeks. Nonoliguric cases were $6(20 \%)$ with mortality of $16.6 \%$. In this study, we observed oliguric ARF in majority of our patients. Higher incidence of oliguric renal failure in falciparum malaria has been reported previously (Prakash J et al 2003, Naqvi R et al 2003 and Wilairatana $P$ et al 1999).12 Nonoliguric patients maintain higher level of glomerular filtrations than do oliguric patients and maintain higher excretion rate of nitrogen, water and acids. The corner stone of treatment of malarial ARF is antimalarial, but early intervention with renal replacement therapy in the form of haemodialysis is associated with improved survival and recovery of renal function. In our study, out of 24 cases of oliguric renal failure 17 (70.8\%) were managed with haemodialysis. Dialysis was done in 2 cases $(33.3 \%)$ of nonoliguric renal failure. The criteria for selection of patient for haemodialysis were clinical assessment, urine output, rising trend of BUN, serum creatinine and dyselectrolytaemia. Haemodialysis appears to be beneficial for ARF associated with malaria, particularly when started earlier in the course of illness (Wilairatana P et al 1999). Greater proportion of patients requiring the haemodialysis in malarial ARF has been documented in the past studies (Mehta KS et al 2001, Prakash J et al 2003, Naqvi R et al 2003 and Wilairatana P et al 1999). In non-oliguric patients, dialysis was also needed for additional removal of waste products since the remaining renal function could not cope with hypercatabolic state. In our study antimalarials were given in all the 30 cases of renal impairment, out of which 11 (36.6\%) having mild renal impairment were managed conservatively with rehydration with mortality of $18.8 \%$ and fewer complications, while 19 (63.3\%) having moderate-to-severe renal impairment and/ or multi-organ failure were managed with haemodialysis with mortality of $47.36 \%$ due to severe complications of malaria with multisystem involvement. The mortality in the dialysis group was more, but it was not significant statistically ( $\mathrm{p}$-value $>0.05$ ).

Though it appears that dialysis was associated with higher mortality in patients with ARF, we here have a selection bias. The patients of ARF were not randomly chosen for dialysis, but only those with deteriorating clinical condition or multi-organ failure were dialysed. They already had a poorer prognosis than those who were not dialysed, so comparison of these two groups is yielding such a result. Out of 30 cases 19 (63.3\%) survived with various treatment regimens in which mean serum creatinine was $3.91 \mathrm{mg} / \mathrm{dL}$, mean serum $\mathrm{Na}^{+}$was $132.26 \mathrm{mEq} / \mathrm{L}$, mean serum $\mathrm{K}^{+}$was 4.26 $\mathrm{mEq} / \mathrm{L}$.

11 cases (36.6\%) who died despite the various management had mean serum creatinine of $8.027 \mathrm{mg} / \mathrm{dL}$, mean serum $\mathrm{Na}^{+}$of $124.64 \mathrm{mEq} / \mathrm{L}$, mean serum $\mathrm{K}^{+}$of 4.98 $\mathrm{mEq} / \mathrm{L}$. Above findings suggested that rising level of serum creatinine, serum $\mathrm{K}^{+}$and decrease in serum $\mathrm{Na}^{+}$bear poor prognosis.

The recovery of renal function was quick in survivors, especially those who were non-oliguric on admission and had less severe renal dysfunction. In malarial ARF prognosis 
depends on the severity of the condition, associated extrarenal complications and early institution of antimalarial therapy along with dialysis support. Availability of renal replacement therapy for malarial ARF has been shown to improve the outcome. In a study performed in Vietnam, mortality in patients with malarial ARF was $75 \%$ without dialysis and $26 \%$ when dialysis was available. Here, the authors stated that effective dialysis or ultrafiltration might further reduce the mortality rate (Trang TT et al 1992). In our study, mortality was $36.6 \%$ which is in agreement with other studies conducted in areas with similar pattern of malaria transmission and where dialysis support was available (Mehta KS et al 2001, Prakash J et al 2003, Naqvi R et al 2003 and Lalloo DG et al 1996). ${ }^{13}$

Other risk factors also contributed to mortality in cases of acute renal failure in malaria. Krishnan et al (2003) reported mortality of $6.8 \%$ only among 172 patients with one or no organ failure, whereas mortality rate increased to $48.8 \%$ in 129 patients with multiple organ failure. In our study, renal impairment along with severe anaemia was present in 5 cases (35.7\%). Kocher et al (1997) found similar observation. Thus, ARF associated with multi-organ dysfunction has been vulnerable to death as compared to renal involvement alone. In the present study oliguria, higher concentration of bilirubin, severity of ARF, cerebral malaria, pulmonary oedema/ ARDS were associated with poor prognosis. Most of these findings as a predictor of mortality in malarial ARF and in complicated falciparum malaria are consistent with other studies (Mahakur et al 1992, Lalloo DG et al 1996, Prakash J et al 1996, AK Bhattacharya et al 2001, Mehta KS et al 2001, Naqvi R et al 2003 and Koh KH et al 2004). ${ }^{14}$ Different renal parameters and serum electrolytes in cases of ARF due to malaria with proper treatment and renal replacement therapy in the form of haemodialysis can revert renal parameters to the normal state after six weeks as evidenced by complete disappearance of proteinuria, normal blood urea, serum creatinine, serum sodium, serum potassium and reversal of GFR to normal in all the cases who survived emphasising the reversible nature of renal involvement in $\mathrm{P}$. falciparum malaria. This is in agreement to the similar observation as reported by earlier workers such as Sitprija et al (1967), Bhamarapravati et al (1973), Boonpucknavig V and Sitprija et al (1996), Rath et al (1990) and A Sowunmi et al (1990). ${ }^{15}$

Our results suggest that malaria complicated with ARF is associated with high morbidity and mortality, but early detection and timely therapeutic intervention with appropriate antimalarial and renal replacement therapy in the form of haemodialysis can revert the renal function to normal.

\section{CONCLUSION}

Overall mortality in this study was $36.6 \%$ among the cases of ARF. Oliguria, serum creatinine, dyselectrolytaemia and multisystem involvement were risk factors for death in the study. The overall prognosis of non-oliguric renal failure was far better than oliguric renal failure. The patients who developed oliguric renal failure had biochemical parameters higher than non-oliguric renal failure patients. Patients with milder renal impairment not requiring dialysis had a better prognosis. It seems likely the patients who fared worse did so because of multisystem dysfunction and more severe renal impairment. It is therefore suggested that early diagnosis of falciparum malaria and prompt treatment may help in preventing many of the devastating complications of their disease including renal or multi-organ dysfunction.

\section{REFERENCES}

[1] Abdalla S, Weatherall DJ, Wickramasinghe SN, et al. The anaemia of $\mathrm{P}$. falciparum malaria. Br J Haematol 1980;46(2):171-83.

[2] Ahmad SH, Danish T, Faridi MMA, et al. Renal function in acute malaria in children. J Trop Pediatr 1989;35(6):291-4.

[3] Mockenhaupt FP, Ehrhardt S, Burkhardt J, et al. Manifestation and outcome of severe malaria in children in northern Ghana. Am J Trop Med Hyg 2004;71(2):167-72.

[4] Das BS. Renal failure in malaria. J Vector Borne Dis 2008;45(2):83-97.

[5] Bag S, Sarmal GC, Deep N, et al. Complicated falciparum malaria. Indian Paediatr 1994;31(7):821-5.

[6] Barsoum R, Sitprija V. Tropical nephrology. In: Diseases of the Kidney. $6^{\text {th }}$ edn. edited by Schrier RW, Gottaschalk CW, Boston, Little, Brown \& Co, 1996:2221-68.

[7] Barsoum RS. Malarial nephropathies. Nephrol Dial Transplant 1998;13(6):1588-97.

[8] Beadle C, Long GW, Weiss WR, et al. Diagnosis of malaria by detection of plasmodium falciparum HRP-2 antigen with a rapid-dipstick antigen capture assay. Lancet 1994;343(8897):564-8.

[9] Berkley J, Mwarumba S, Bramham K, et al. Bacteraemia complicating severe malaria in children. Trans R Soc Trop Med Hyg 1999;93(3):283-6.

[10] Boonpucknavig V, Sitprija V. Renal disease in acute plasmodium falciparum infection in man. Kidney Int 1979;16(1):44-52.

[11] Breman JG. The ears of the hippopotamus: manifestations, determinants, and estimates of the malaria burden. Am J Trop Med Hug 2001;64(1,2):111.

[12] Prakash J, Gupta A, Kumar 0, et al. Acute renal failure in falciparum malaria--increasing prevalence in some areas of India--a need for awareness. Nephrol Dial Transplant 1996;11(12):2414-6.

[13] Naqvi R, Ahmad E, Akhtar F, et al. Outcome in severe acute renal failure associated with malaria. Nephrol Dial Transplant 2003;18(9):1820-3.

[14] Barsoum RS. Malarial acute renal failure. J Am Soc Nephrol 2000;11(11):2147-54.

[15] Rastegar A, Sitprija V, Rocha H. Tropical Nephrology. In: Diseases of the kidney. $5^{\text {th }}$ edn. Schrier RW, Gottschalk CW, (eds). Little, Brown and Company, New York, 2017:2331-60. 